\title{
ANALYSIS OF THE DISTRIBUTION OF CHEMICAL COMPOUNDS FROM FLY ASH EXPOSED TO WEATHER CONDITIONS
}

\author{
Aleksandra Sambor ${ }^{*}$, Arkadiusz Szymanek \\ Czestochowa University of Technology, Department of Engineering and Environmental Protection, \\ Institute of Advanced Energy Technologies, ul. Dąbrowskiego 73, 42 -200 Częstochowa, Poland
}

\begin{abstract}
The paper presents investigation results of the migration of a chemical compound contained in fly ash deposited on a dry furnace waste landfill site exposed to weather conditions. Climate conditions are able to significantly affect chemical component distribution in a block of deposited, moving chemical compounds to different depths. The main aim of the investigations was to determine the chemical component distribution of deposited fly ash in the landfill. Identification of chemical components based on XRF analysis indicated the existence of differences in both tested storage layer and the fraction of fly ash.
\end{abstract}

Keywords: landfill, migration, fly ash, chemical compounds, weather conditions

\section{INTRODUCTION}

In the Polish electric power sector, coal has invariably a leading position. In 2008 alone, about $90 \%$ of electric energy was generated from fossil fuels, 55\% from hard coal and 35\% from brown coal. Significant resources of solid fuels determine Poland's energy self-sufficiency. One of the priorities of "Poland's energy policy until 2030" is to maintain this significant role of hard and brown coals for the energy industry and for the processes of their thermochemical conversion (Uliasz-Bocheńczyk et al., 2010). A strategic direction of the energy policy is also to increase the degree of management of combustion by-products formed during the processes of thermochemical coal conversion. According to fuel balance forecasts for the next 30 years, maintaining the share of coal at the existing level is tantamount to the increase in the amount of combusted coal from 5370 million tons in 2006 to 10560 million tons in 2030. Assuming that at least $60 \%$ of combusted coal will be used for the production of electric energy, the amount of coal combustion by-products will increase from around 480 million tons to as much as 950 million tons. Statistically, burning of 1 million tons of coal in the electric energy generation process will generate 120 thousand tons of fly ash, of which 40 to $80 \%$ still end up on furnace waste landfills. Around 20 million tons of fly ash per year are generated in Poland, with the Silesian Province alone having generated 1527.3 thousand tons of fly ash in 2010 (Hycnar and Szczygielski, 2008). Currently, the total amount of landfilled wastes is approx. 250 million tons, with part of them being already inaccessible due to land reclamation carried out. The actual amount of hard coal combustion by-products, being in the custody of the power industry and local authorities, exceeds 120 million tons. Therefore, as a European Union member, Poland has pledged to establish its own strategy aimed at reducing the amount of landfilled wasted and preventing or minimizing the adverse impacts of the landfilled furnace wasted on the environment. The main negative aspects of landfilling fly ash include: taking up considerable areas of land for landfills, the impact of waste dump infiltrating water on 
the underground water, and the change in surface water quality by discharging waste dump infiltrating water to the surface water. Fly ash disposed of on a landfill site causes also the pollution of the air and the adjacent areas and plants by dust carried away from the landfill surface. Therefore, any method of fly ash management would be better that disposing of the fly ash onto waste dumps, where it only poses economic and environmental problems (Hycnar et al., 2010). The furnace waste dump body is subject to the action of natural environmental media. Under their influence, the structure of wastes piled up on the waste dump starts to transform. The basic and most important factor shaping the physicochemical nature of the energy waste body is water. Process and heavily mineralised supernatant waters, as well as precipitation water are involved here. The sum of these influences results in the transformation of the landfilled waste structure. As a result, a number of chemical and physical changes occur in the waste bed (Lączny and Adamski, 2002).

A measure of the examined environmental impact on the landfill site is the increase of the concentration of pollutants in ground water (Adamek and Kobus, 1996; Woźniak and Klisik, 2007). The intensity and range of furnace waste environmental impact depends largely on the physicochemical properties of the waste, pollutant concentration in the filtrate, landfilling technology, and the structure and location of the landfill. As the characteristic feature of furnace waste is the dissolvability of some constituents in contact with water, then, depending on the coal raw-material and the installation type, 3 to $10 \%$ of substances may be washed out from the initial ash mass. In natural conditions on wet waste dumps, whenthe ash is fully wetted with water, the liquid phase becomes saturated with sodium, potassium, calcium, magnesium, sulphate and chloride ions.

The rate of dissolution of constituents, and so their release into the environment, varies. The dissolvability of furnace ashes depends on their chemical composition. Also $\mathrm{OH}^{-}$ions are liberated, which causes a change in the $\mathrm{pH}$ value even up to 10-12 (Choi et al. 2002; Łączny and Adamski, 2002a). An essential characteristic of waste, in addition to the mobility of pollutants, are the effects of waste ageing, which can be either advantageous or adverse. Investigation of the leachability of pollutants from fly ash conveyed in the form of emulgate, carried out by (Klojzy-Kaczmarczyk and Mazurek, 2003), has shown that the chemical constituents which are leached from the ash to the water solution are primarily $\mathrm{SO}_{4}{ }^{2-}$, $\mathrm{Ca}^{2+}$. Conversely, in water extracts from ash with a high sulphur content, $\mathrm{SO}_{4}{ }^{2-}, \mathrm{Ca}^{2+}$ and $\mathrm{OH}^{-}$prevail, and the total amount of pollutants leached from such ash is more than 4 times as high as that for sulphurfree ash. A high $\mathrm{pH}$ value only occurs, however, in the initial period of landfilling ahs-water emulgates. Bonding processes occur on waste dumps, which, as a consequence, alter the nature of water extracts discharged to the environment. The $\mathrm{pH}$ reaction lowers, and after completion of the bonding processes, it is close to the neutral one. Thus, the properties of waste dump effluents are strongly influenced by the age of the deposited ash (Rosik-Dulewska and Karwaczyńska, 2008). Chemicals which partake in leaching are also waste heavy metals condensed on fly ahs particles, which change into a gaseous state during combustion, and as a result of precipitation on dry waste dumps and due to the contact with process water on wet waste dumps, they are washed off from the surface of the particles and penetrate into the soil and ground water, and then to living organisms. If the deposited waste has an alkaline reaction, then the main environmental hazard will be posed by liberating sodium, potassium and calcium sulphates (Lecuyer et al., 1996). A particular danger is caused by acid precipitation which, due to its aggressiveness, promotes the solubility of those compounds. Many years' studies (Quant, 2000) have proved that in the fly ash landfilling conditions there is a possibility that as much as approx. 1/3 of the total heavy metals contents will be leached from the ash, while depositing ash in a manner that facilitates water to infiltrate through the ash layer considerably increases the potential of heavy metals to be washed out in a proportion of even more than $80 \%$ (Kwiatkowska et al., 2006). The literature lacks information on the effect of climatic conditions and erosion processes on the stability of the fly ash particle structure, which is undoubtedly associated with the susceptibility of chemical compounds to being leached to water and soil (Woźniak and Żygadło, 2002). Moreover, the current requirements concerning the environmental impact of coal-fired power plants and combustion by-products are extended by the necessity of reducing the emission of mercury. Depending on the mercury elimination method applied, a part of fly ash is likely 
to be excluded from being used in construction and, as a consequence, it will be required to be landfilled. Research carried out by (Watanabe et al., 2008) has shown that the amount of dissolved solid substance is in the range from 1.0 to $1.7 \%$. In natural conditions, with a single ash contact with water, few water soluble substances contained in the waste $(20 \div 30 \%)$ pass to the water, accounting for a mere $0.5-1 \%$ of the ash dry matter. Only a repeated contact between water and ash does result in a greater degree of their leaching (30-50\% of soluble matter), amounting to $1-1.5 \%$ of dry waste matter. Generally, it is observed that with an increasing number of times of washing ash with water, (atmospheric deposition) the amount of compounds leached from the ash is decreasing. However, the methods of determining the leachability of ash still remain a disputable issue. Using the methodology developed for wastes is often means disregarding the mechanisms of changes occurring in the structure of fly ash, which exhibits the properties of pozzolana. Any ashes are disqualified because of the increased $\mathrm{pH}$ of their water extracts, which, in the conditions of their use, is irrelevant, as those ashes undergo then petrifaction, etc. There is a general view about the need for developing a determination method and assessment criteria adequate to the combustion by-product properties (Sambor and Szymanek, 2012; Watanabe et al., 2008). Trace elements ( $\mathrm{Fe}, \mathrm{Zn}, \mathrm{Cu}, \mathrm{Mn}, \mathrm{Cr}, \mathrm{Co}, \mathrm{Se}, \mathrm{Sn}, \mathrm{I}, \mathrm{V}, \mathrm{B}, \mathrm{Li}, \mathrm{Ni}, \mathrm{Al}$ ) occur in negligible amounts in ash, accounting for $0.1-0.3 \%$ of the overall waste mass. Trace elements are hard to leach and their contents in the water extract are often at the limit of detectability, only in sporadic instances exceeding the permissible limits for potable and surface waters. Of microelements, boron and cadmium are the most readily soluble. The minimum solubility of heavy metals is caused by a strongly alkaline reaction of ash water extracts $(\mathrm{pH}=9.0-12.0)$. The exception is chromium, whose solubility increases with the increase in alkaline reaction (Rosik-Dulewska and Karwaczyńska, 2008). On the other hand, research carried out by Woźniak and Klisik (2007) showed that higher contents of elements, such as $\mathrm{Cd}, \mathrm{Co}, \mathrm{Cr}, \mathrm{Mn}, \mathrm{Ni}$ and $\mathrm{Zn}$ were observed in a water eluat from fresh ash, compared to a year's old ash, and that for $\mathrm{Cd}, \mathrm{Co}, \mathrm{Cr}$, $\mathrm{Ti}, \mathrm{Zn}$, the reaction had no clear effect on their ash leachability, whereas a slightly acid reaction $(\mathrm{pH}=5)$ would promote $\mathrm{Pb}$ and $\mathrm{Fe}$ compounds to be leached from the ash, and at $\mathrm{pH}=7-8, \mathrm{Cu}$ compounds would be leached to the solution to a maximum extent. The degree of leaching is also influenced by the contents of calcium and magnesium oxides - the larger their contents, the higher the leaching degree. A study by Strzałkowska (2004) on the presence of toxic elements in fly ash has found that the vast majority of them are concentrated in the structures of stable aluminosilicate phases that are either only slightly leached, or not leached at all, with water, thus posing no hazard to ground water. This high stability of aluminosilicates is associated with the low mobility of aluminium ions which, in the presence of strong inorganic acids, will not pass to the solution. However, in the natural environment, leaching of aluminium from aluminosilicates does occur due to the formation of water insoluble organoaluminium complex compounds. Because of the possibility of fluctuations in the $\mathrm{pH}$ of water solutions promoting the liberation of humic acids, which are to be found within the furnace waste body, a considerable increase in the mobility of aluminosilicate aluminium may occur, leading to the leaching of toxic elements. Another study (Kapuściński and Strzałkowska, 2005) found that the leaching of aluminium and silicate from the aluminosilicate matrix resulted in a disruption of its structure and liberation of $\mathrm{Cr}, \mathrm{Ni}, \mathrm{V}, \mathrm{Zn}$ and As. Moreover, the effect of polyaromatic hydrocarbons (PAHs) absorbed on the surface of ash particles can be very dangerous, because being washed out by precipitation, they will penetrate into the soil and ground water (Quant, 2000). For the leachate characterisation, recognition and accurate analysis of the chemical composition of the deposited fly ash has a major impact.

\section{PURPOSE OF THE INVESTIGATION}

The purpose of the present investigation was to identify chemical components contained in fly ash derived from the combustion of hard coal in stoker-fired and pulverized-fuel boilers, which were stored at different depths of a dry furnace waste dump for 40 years. As the parameters decisive to the utilisation of fly ash in the building industry is its flammable matter contents, which must not exceed 5\%, the results obtained from the examination of chemical composition were related to the percentage of carbon content. 
Hence, in order to accurately identify the distribution of chemical components within the whole body of a waste dump, it is important to determine the effect of climatic conditions on their distribution in the selected layers of the dump, as well as in specific fly ash fractions. The paper presents the identification of chemical compounds depending on the waste dump depth, the $\mathrm{pH}$, structure and topography of the fly ash, and the thermogravimetric analysis of flammable matter. It is a continuation of the research published in Chemical and Process Engineering entitled "Investigation of the distribution of chemical components in selected landfill layers and fly ash fractions" (Sambor and Szymanek, 2012).

\section{EXPERIMENTAL}

The test material was taken from a combustion waste dump with a container area of $67000 \mathrm{~m}^{2}$, whose total cubage is $283500 \mathrm{~m}^{3}$ and a usable container cubage is $216500 \mathrm{~m}^{3}$. Fly ash originating from a power plant was deposited on that waste dump by the dry method starting from the early 1970s. On the landfill, 50 representative measurement points were set, from which, using a handheld geotechnical survey set, 6 samples were taken from all spots of $0,0.5 \mathrm{~m}, 1 \mathrm{~m}, 1.5 \mathrm{~m}, 2 \mathrm{~m}$, and $2.5 \mathrm{~m}$. A total of 297 samples were taken from each depth. During sampling of the material, the geographical coordinates of all 50 measurement points were recorded for the subsequent processing of results using a GIS (Geographical Information System). The software program, along with its relevant extensions, will allow the collection of testing results and their visualisation, depending on the spatial positioning, landfill layer, or a specific fly ash fraction. It will also enable the database to be extended by adding further testing results. The following diagrams present the average values of undertaken measurement from all points and depths.

\subsection{Determination of the distribution of elements and chemical compounds}

The identification of chemical compounds was done using X-ray fluorescence (XRF) spectrometry using an ED-XRF energy-dispersion analyser according to the applicable standard PN- 77/G-04528. The distribution and percentage fraction of chemical compounds of individual landfill layers were determined, as shown in diagrams I, II and III.

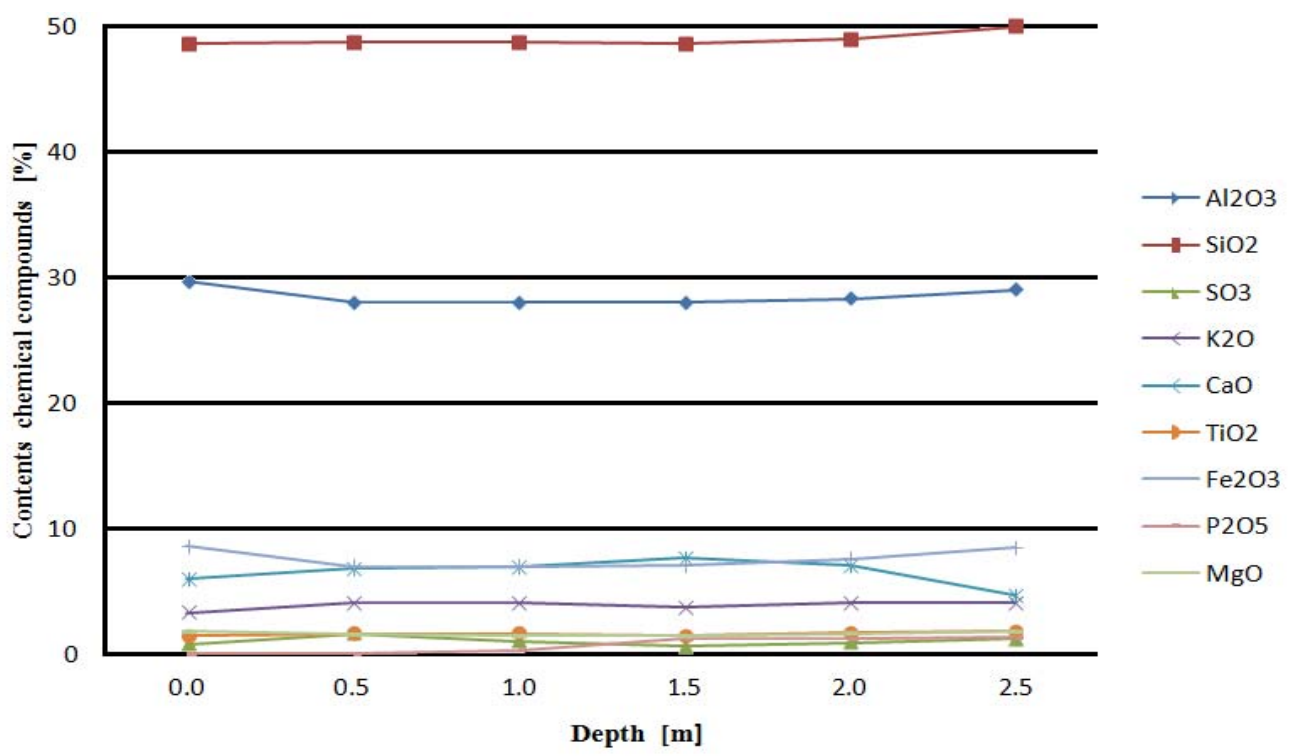

Fig. 1. Relationship of chemical compound concentration vs. depth - Part I

The chemical compounds $\mathrm{Al}_{2} \mathrm{O}_{3}, \mathrm{CaO}, \mathrm{Fe}_{2} \mathrm{O}_{3}$ showed the greatest concentrations on the landfill surface denoted by " 0 " $\mathrm{m}$, whereas at a depth of $0.5 \mathrm{~m}$, a considerable decrease in concentration values could be 
noticed; $1 ; 1.5 ; 2$; and $2.5 \mathrm{~m}$ are the depth, at which an increase in concentrations was observed, though not exceeding the percentage fractions noted on surface 0 . For $\mathrm{SiO}_{2}, \mathrm{TiO}_{2}, \mathrm{~K} 2 \mathrm{O}$, these values increase steadily from the $0 \mathrm{~m}$ layer and attain a maximum at $2.5 \mathrm{~m}$. Magnesium oxide $(\mathrm{MgO})$, on the other hand, attained a value of $1.75 \%$ on the landfill surface $0 \mathrm{~m}$, then concentration values decreased with depth, achieving a maximum of $1.80 \%$ at the deepest landfill layer. For sulphur(VI) oxide, the highest concentration could be noticed at a depth of $0.5 \mathrm{~m}$, which was as high as $1.6 \%$. Phosphorus (V) oxide turned out to be a special case as, it was not identified at the shallowest landfill layers; only at a depth of $1 \mathrm{~m}$ was its slight fraction observed, which continued to increase, and then at a depth of $2.5 \mathrm{~m}$ attained a value of $1.3 \%$. The remaining values are presented in Fig. 2.

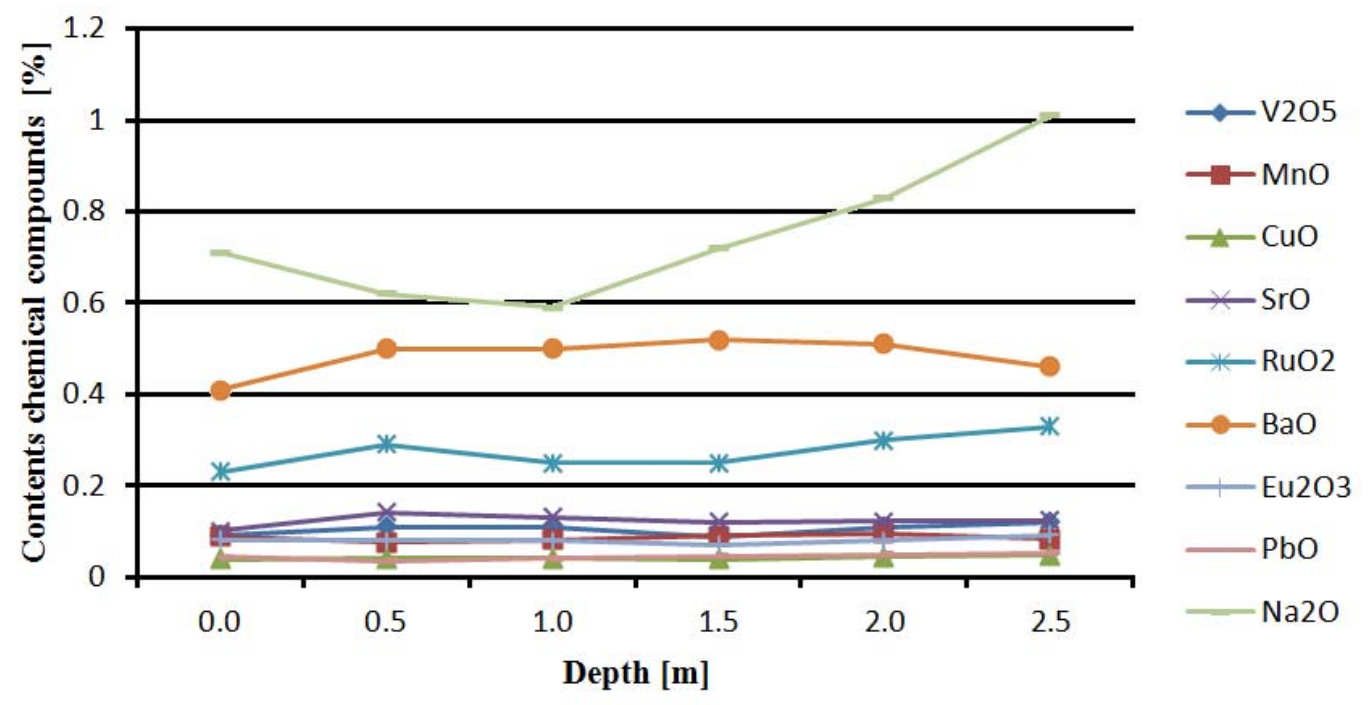

Fig. 2. Relationship of chemical compound concentration vs. depth - Part II

Copper (II) oxide is characterised by a steady increase of values from 0 to $2.5 \mathrm{~m}$. In contrast, manganese, sodium, lead and europium oxides all showed high values on the landfill surface $0 \mathrm{~m}$, after which their values slightly decreased at $0.5 \mathrm{~m}$ and stabilised at the remaining depths, at the greatest depth attaining values higher than those for $0 \mathrm{~m}$. For barium, vanadium and ruthenium oxides, the highest values were noted at depths of 0.5-2.0 m. Strontium oxide showed stable values at all depths.

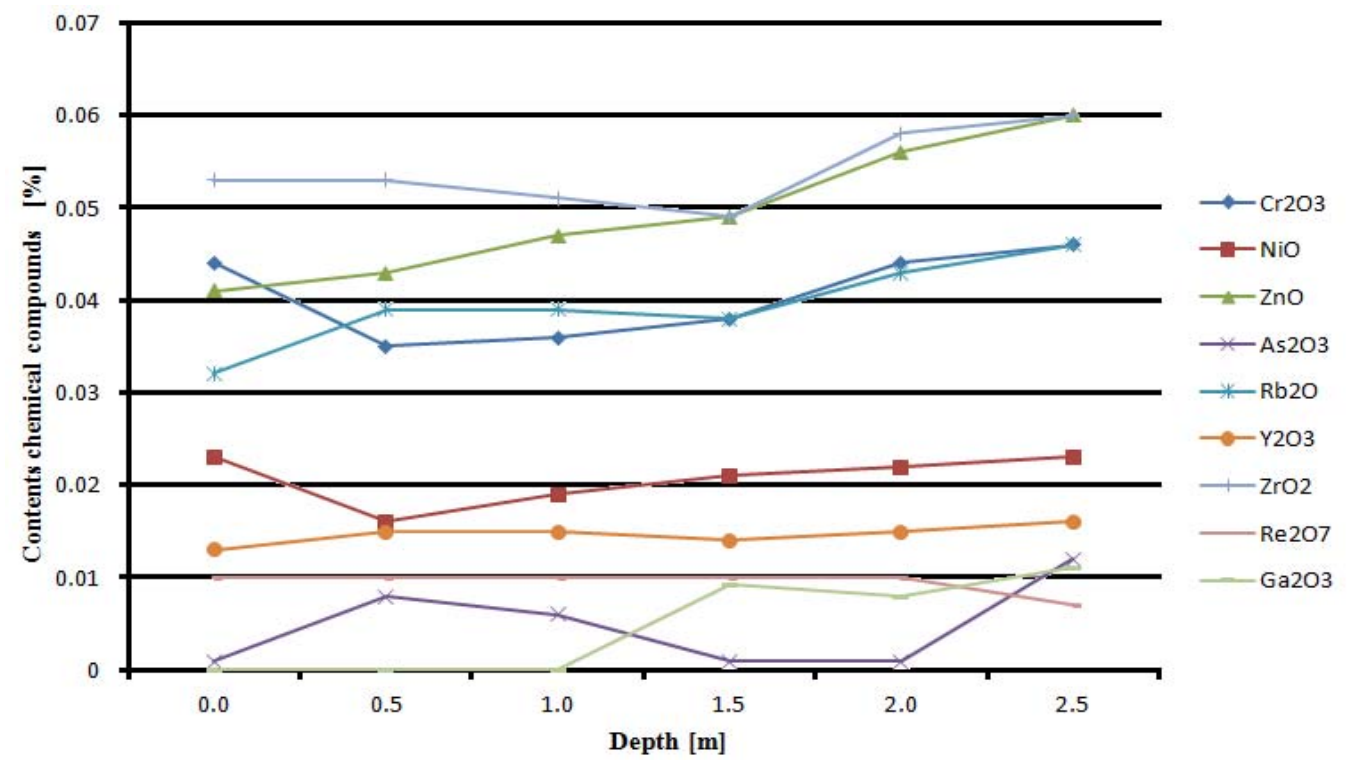

Fig. 3. Relationship of chemical compound concentration vs. depth - Part III 
Chromium, nickel and zirconium oxides showed high values at depths of 0 and $2.5 \mathrm{~m}$, with their values at the remaining landfill depths being lower and stabilised. Similarly as $\mathrm{P}_{2} \mathrm{O}_{5}$, gallium oxide was not identified at the shallowest landfill layers up to a depth of $1.5 \mathrm{~m}$, where its slight fraction was observed, which then increased to attain a maximum at a depth of $2.5 \mathrm{~m}$. Also rhenium oxide exhibited stable values at all depths. On the other hand, a steady increase in the percentage fraction from the lowest to the highest depth was shown by zinc, arsenic, rubidium and yttrium oxides.

Analysing these data, it can be concluded that, within the landfill there is a migration of chemical components of fly ash. Among the examined depths: $0,0.51,1.5,2,2.5 \mathrm{~m}$ the largest differences in the relation to both qualitative and quantitative chemical components shown area 0 and the lowest depth of $2.5 \mathrm{~m}$. Generalising the analising surface may be combined of 0 and $0.5,1$ and 1.5 , and 2 and 2.5 because concentrations of the investigated chemicals in these groups revealed some similarities.

Moreover, the analysis of the dependence of chemical compound concentrations on the percentage concentration of carbon was also made for a carbon content below $10 \%$, from 10 to $20 \%$, and above $20 \%$. Carbon and sulphur identification examination results are provided by (Sambor and Szymanek 2012). The following data in the table present the average values of undertaken measurement from all points and depths.

Table 1. Dependence of chemical compound concentrations on carbon content

\begin{tabular}{|c|c|c|c|}
\hline Chemical compound & $\begin{array}{c}\mathrm{C} \text { content } \\
\text { From } 0 \text { to } 10 \%\end{array}$ & $\begin{array}{c}\mathrm{C} \text { content } \\
\text { from } 10 \text { to } 20 \%\end{array}$ & $\begin{array}{c}\text { C content } \\
\text { above } 20 \%\end{array}$ \\
\hline \multicolumn{4}{|c|}{ Matrix elements } \\
\hline $\mathrm{SiO}_{2}$ & 48 & 50.3 & 48.9 \\
\hline $\mathrm{Al}_{2} \mathrm{O}_{3}$ & 31 & 29 & 29 \\
\hline $\mathrm{Fe}_{2} \mathrm{O}_{3}$ & 6.82 & 9.31 & 8.24 \\
\hline \multicolumn{4}{|c|}{ Principal elements } \\
\hline $\mathrm{CaO}$ & 5.84 & 4.42 & 5.15 \\
\hline $\mathrm{K}_{2} \mathrm{O}$ & 3.14 & 3.82 & 4.3 \\
\hline $\mathrm{SO}_{3}$ & 2.7 & 1.7 & 1.2 \\
\hline $\mathrm{TiO}_{2}$ & 1.4 & 1.69 & 1.89 \\
\hline $\mathrm{MgO}$ & 1.24 & 1.30 & 1.40 \\
\hline $\mathrm{Na}_{2} \mathrm{O}$ & 0.71 & 0.77 & 0.83 \\
\hline $\mathrm{P}_{2} \mathrm{O}_{5}$ & 0.01 & 0.75 & 0.90 \\
\hline \multicolumn{4}{|c|}{ Trace elements } \\
\hline $\mathrm{V}_{2} \mathrm{O}_{5}$ & 0.092 & 0.12 & 0.13 \\
\hline $\mathrm{Cr}_{2} \mathrm{O}_{3}$ & 0.049 & 0.045 & 0.05 \\
\hline $\mathrm{MnO}$ & 0.067 & 0.092 & 0.084 \\
\hline $\mathrm{NiO}$ & 0.023 & 0.023 & 0.024 \\
\hline $\mathrm{CuO}$ & 0.039 & 0.044 & 0.053 \\
\hline $\mathrm{ZnO}$ & 0.034 & 0.071 & 0.056 \\
\hline $\mathrm{As}_{2} \mathrm{O}_{3}$ & 0.001 & 0.003 & 0.006 \\
\hline $\mathrm{Rb}_{2} \mathrm{O}$ & 0.03 & 0.041 & 0.061 \\
\hline $\mathrm{SrO}$ & 0.1 & 0.12 & 0.13 \\
\hline $\mathrm{Y}_{2} \mathrm{O}_{3}$ & 0.013 & 0.016 & 0.017 \\
\hline $\mathrm{ZrO}_{2}$ & 0.048 & 0.06 & 0.062 \\
\hline $\mathrm{RuO}_{2}$ & 0.23 & 0.29 & 0.36 \\
\hline $\mathrm{BaO}$ & 0.32 & 0.46 & 0.47 \\
\hline $\mathrm{Eu}_{2} \mathrm{O}_{3}$ & 0.07 & 0.096 & 0.09 \\
\hline $\mathrm{Re}_{2} \mathrm{O}_{7}$ & 0.0 & 0.005 & 0.01 \\
\hline $\mathrm{PbO}$ & 0.04 & 0.058 & 0.049 \\
\hline $\mathrm{Ga}_{2} \mathrm{O}_{3}$ & 0.0 & 0.011 & 0.0 \\
\hline
\end{tabular}


As was shown by the tests carried out for the carbon content ranging from 0 to $10 \%$, the highest percentages were found for chemical compounds, such as $\mathrm{Al}_{2} \mathrm{O}_{3}, \mathrm{CaO}$ and $\mathrm{SO}_{3}$. More chemical compounds attained their highest concentrations in the carbon content range of 10-20\%; these include: $\mathrm{SiO}_{2}, \mathrm{Fe}_{2} \mathrm{O}_{3}, \mathrm{ZnO}, \mathrm{PbO}, \mathrm{Ga}_{2} \mathrm{O}_{3}$ and $\mathrm{Eu}_{2} \mathrm{O}_{3}$. However, the remaining 18 chemical compounds displayed the highest concentration values in the carbon content range above $20 \%$ carbon. The determination of this correlation is an important aspect when a decision which process of fly ash management should be chosen.

\section{2. $\mathrm{pH}$ determination}

The determination of $\mathrm{pH}$ was made according to the applicable standard PN-ISO 10390. From a representative ash mass of $5 \mathrm{~g}$ (from all depths and samples), ash suspension was prepared, which was subsequently shaken for 5-10 minutes and then left for a duration of $2 \mathrm{hrs,} \mathrm{after} \mathrm{which} \mathrm{the} \mathrm{readings} \mathrm{of} \mathrm{pH}$ and $\mathrm{T}$ were taken. The ash suspensions exhibited an alkaline reaction in all samples (Fig. 4).

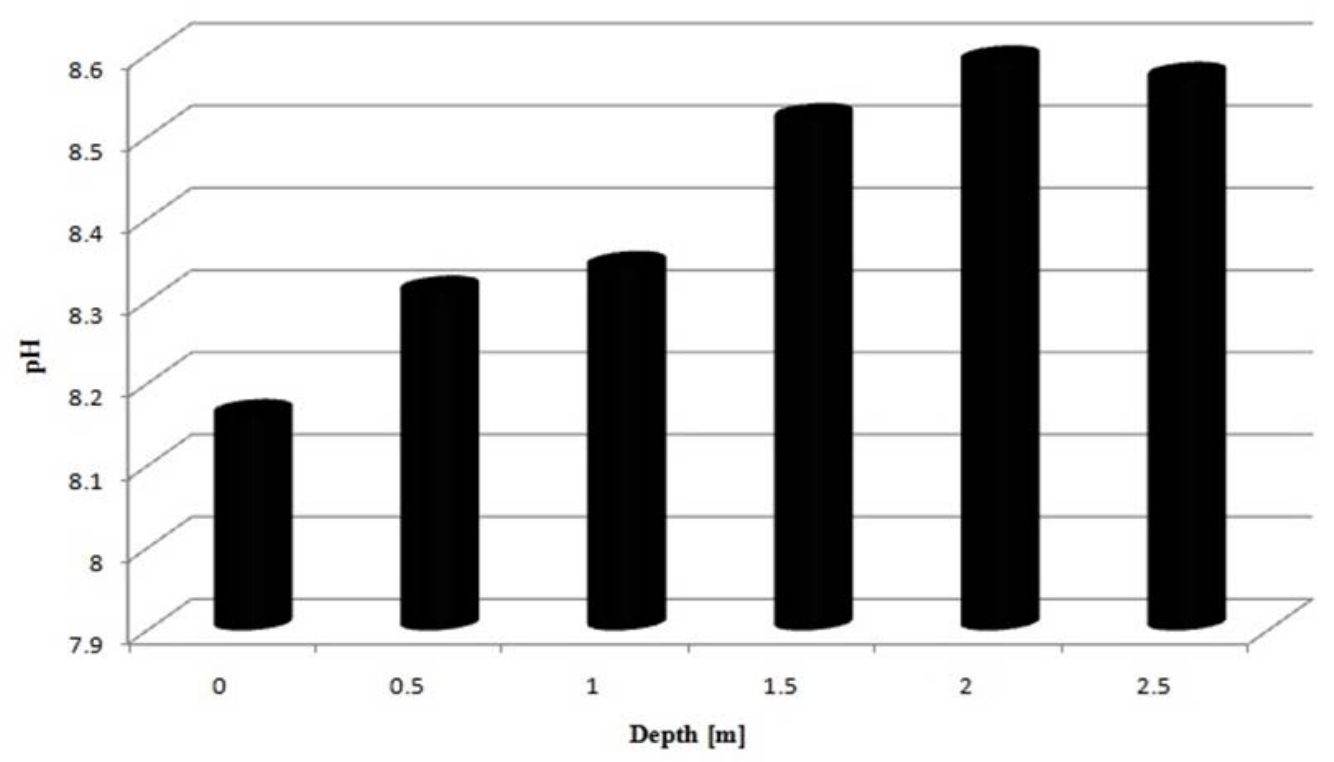

Fig. 4. Relationship of the value of $\mathrm{pH}$ vs. depth

The mean $\mathrm{pH}$ values varied with depth. The lowest $\mathrm{pH}$ value was measured for all samples taken from the $0 \mathrm{~m}$ depth, whereas the highest $\mathrm{pH}$ value of 8.6 was attained at a depth of 2 and $2.5 \mathrm{~m}$, which is indicative of the effect of weather factors on the leaching of chemical compounds and passing of $\left[\mathrm{OH}^{-}\right]$ions into the landfill body.

On the landfill surface $(0 \mathrm{~m})$, the chemical compounds $\mathrm{Al}_{2} \mathrm{O}_{3}, \mathrm{CaO}$ and $\mathrm{Fe}_{2} \mathrm{O}_{3}$ had the highest concentrations, which is associated with the lowest $\mathrm{pH}$ reaction of 8.13 . For a landfill depth of $0.5 \mathrm{~m}$, the highest concentration was exhibited by $\mathrm{SO}_{3}$. At a landfill depth of $2.5 \mathrm{~m}$, the highest concentrations were found for $\mathrm{MgO}, \mathrm{SiO}_{2}, \mathrm{TiO}_{2}, \mathrm{~K}_{2} \mathrm{O}$ and $\mathrm{CuO}$, whose values increased steadily from beneath the depth of 0 $\mathrm{m}$. Also manganese, sodium, lead and europium oxides showed the highest concentrations at this depth, but they also attained high values at the landfill surface, after which their values slightly decreased at 0.5 $\mathrm{m}$ and then stabilised at further depths. Phosphorus (V) oxide and gallium oxide turned out to be a special case as they were not identified in the shallowest landfill layers; only at a depth of 1 and $1.5 \mathrm{~m}$, respectively, where their trace amounts were observed, which then increased to the highest values at a depth of $2.5 \mathrm{~m}$. This is caused by a very fast leaching from the initial landfill layers and subsequent accumulation in the deepest layers. Strontium and rhenium oxides are characterised by stable values at 
all depths, which is indicative of their invariable concentration, being independent of the effect of weather conditions. By contrast, for barium, vanadium and ruthenium oxides, the highest values were noted at depths of $0.5-2.0$, which can be explained by a long and stable process of element migration into the landfill body. Chromium, nickel and zirconium oxides showed high values at depths of 0 and $2.5 \mathrm{~m}$, with their values being lower and stabilised at the remaining landfill depths. Zinc, arsenic, rubidium and yttrium oxides are leached into the landfill body from the lowest to the highest depth.

\subsection{Determination of the fly ash structure}

The determination of the fly ash structure and fly ash topography was done by the semi-contact method using a Vecco Muti Mode V atomic force microscope.

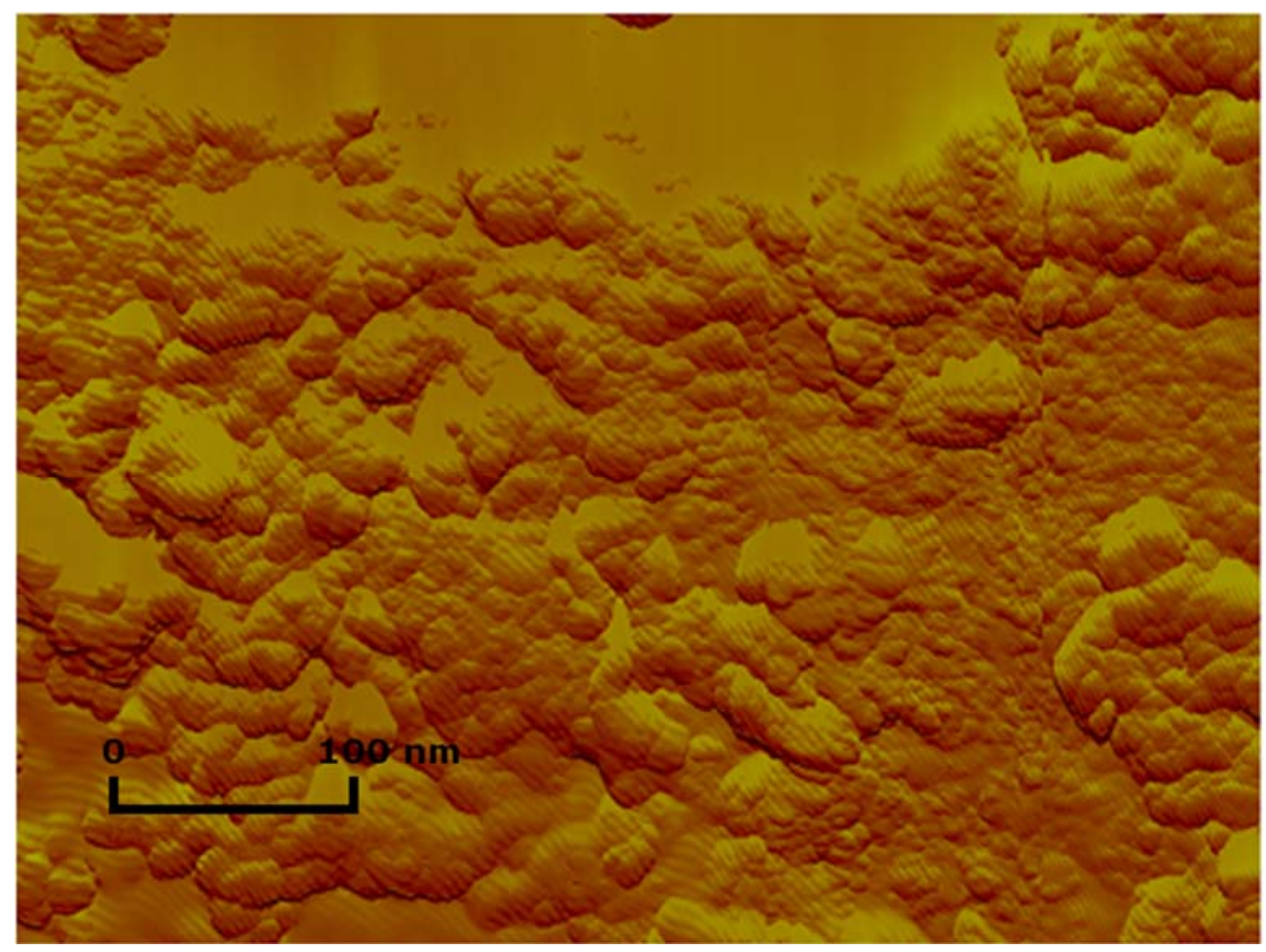

Fig. 5. Specific surface of a fly ash particle - studied area $500 \times 500 \mathrm{~nm}$

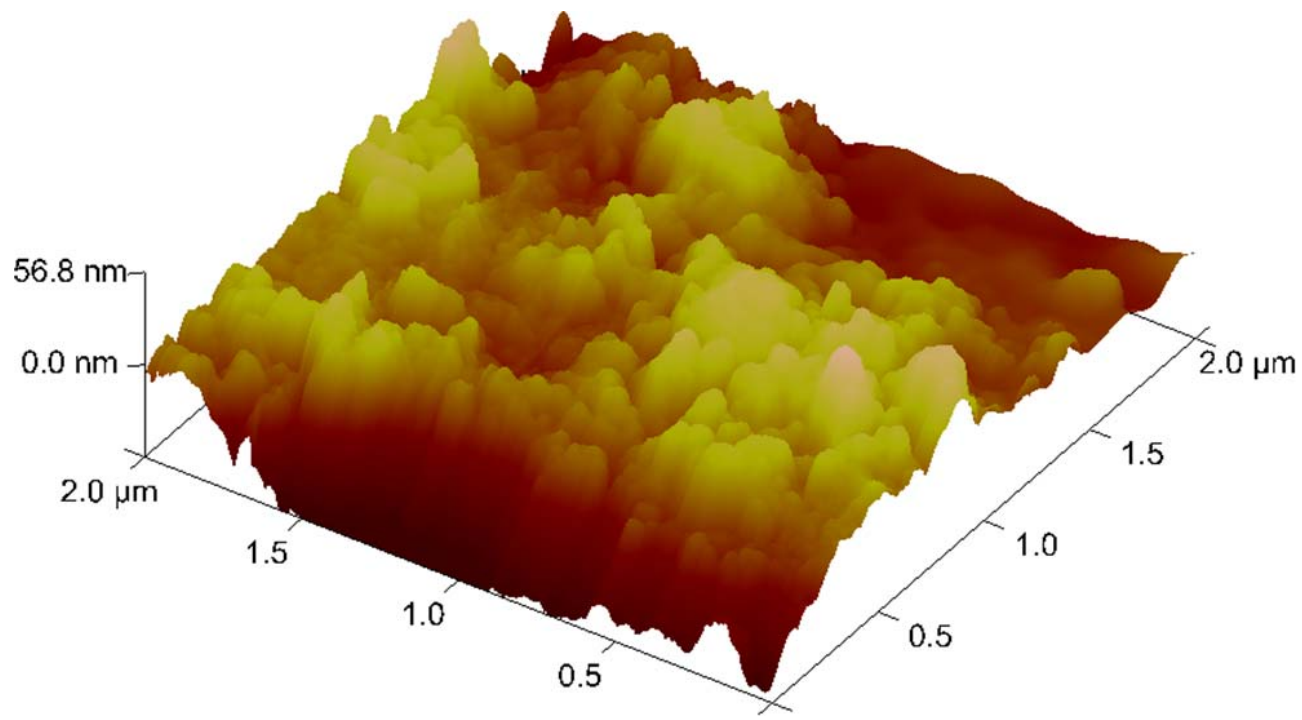

Fig. 6. A three-dimensional image of fly ash particle topography 
Fly ash shows a differential particle-size distribution pattern. The share of the dust and silt fractions determines the filtrating and dusting properties. In gravel and sand fractions (Figs. 5, 6), irregular-form and crumbs and conglomerates prevail, while in dust and silt fractions, regular smoothed particles are more common. The effect of particle-size distribution and structure of fly ahs will be determined in further examination using a specialised software program, ArcGIS.

\subsection{Thermogravimetric analysis of flmmable matter}

The thermogravimetric analysis of flammable matter was made using a TGA/SDTA 851e analyser. The TG curve for the fly ash burned in an inert atmosphere shows a small mass loss in the temperature range from 25 to $200^{\circ} \mathrm{C}$, which is caused by the evaporation of water from the sample. A larger mass loss in the temperature range of $460-1000^{\circ} \mathrm{C}$ is caused by the decomposition of calcium hydroxide and calcium carbonate. The total mass loss during the process amounted to $9 \%$. No other decomposition was found.

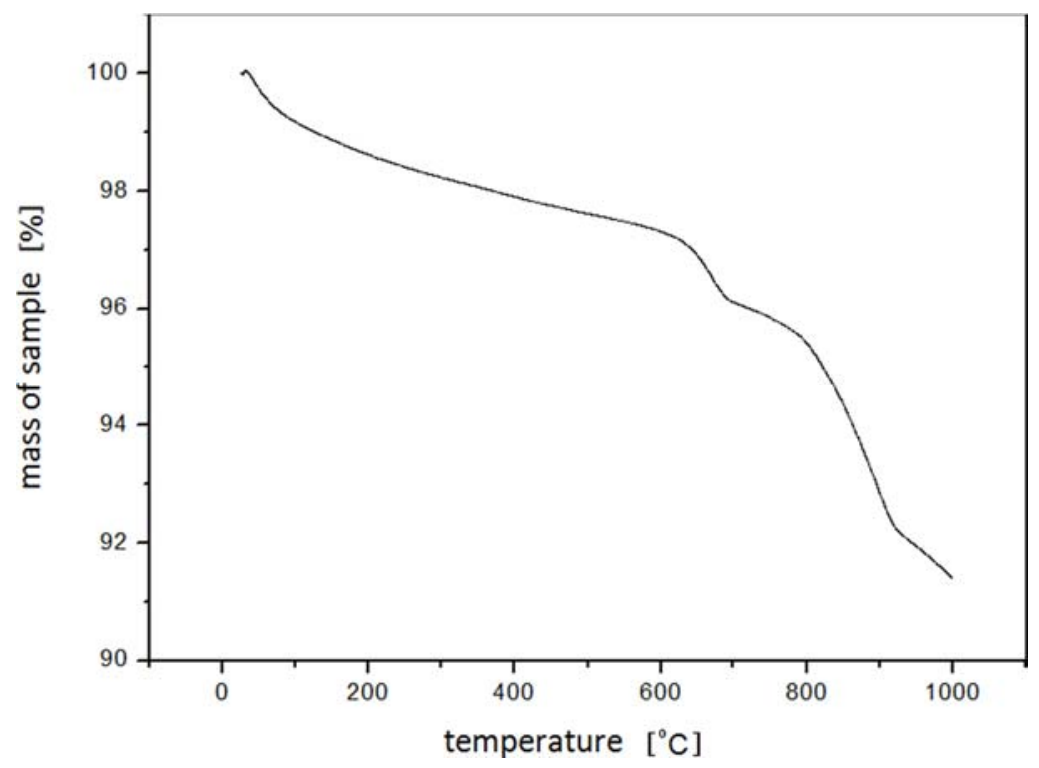

Fig. 7. The TG profile of a fly ash sample

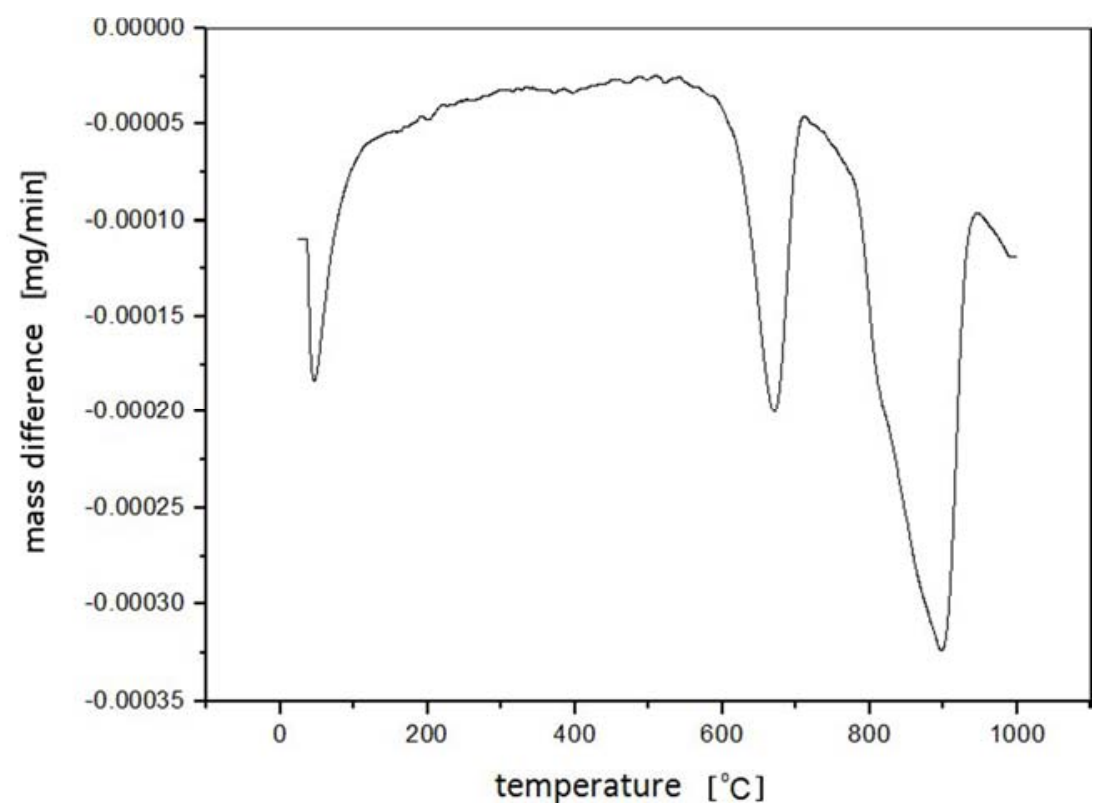

Fig. 8. The DTG profile of a fly ash sample 


\section{CONCLUSIONS}

In summary, it can be concluded that ash waste landfill sites are areas that have a significant impact on the soil and water environment. Their impact on the natural environment is dependent on weather factors, landfilling duration, the $\mathrm{pH}$, chemical composition and concentration of the landfilled fly ash. Increased amounts of dissolved substances can pass together with the filtrate to the surface water, and then to the drinking water intakes. All of the identified chemical compounds are characterised by a varying rate of migration within the landfill layers. A decisive majority of the identified chemical compounds are accumulated at a depth of $2.5 \mathrm{~m}$, which is undoubtedly associated with the effect of weather conditions and temperature changes affecting the waste dump. There are also correlations between the occurrence of chemical compounds and the content of unburned carbon. The results of investigations have also shown an increase in the $\mathrm{pH}$ value from the depth of $0 \mathrm{~m}$ to $2.5 \mathrm{~m}$, whereby the alkaline reaction promotes the leaching of chemical compounds into the landfill body. The landfilled fly ash chemical compounds are extremely desirable in many sectors of the economy and their low fractions of trace elements determine the safety of their economic utilisation. Therefore, it is essential to conduct constant monitoring of furnace waste landfill sites and to extend the scope of conducted investigations.

The author was awarded a scholarship within the framework of the DoktoRIS project - The scholarship programme for the innovative Silesia co-financed by the European Union under the European Social Fund.

\section{SYMBOLS}

$\begin{array}{ll}D T G & \text { Derivative Thermogravimetry } \\ \text { GIS } & \text { Geographic Information System } \\ \text { PAHs } & \text { Polycyclic Aromatic Hydrocarbons } \\ \text { SDTA } & \text { Simultaneous Differential Thermal Analysis } \\ T G A & \text { Thermogravimetric Analysis } \\ T G & \text { Thermal Gravimetry } \\ X R F & \text { X-ray fluorescence spectrometry }\end{array}$

\section{REFERENCES}

Adamek E., Kobus A., 1996. Impact of power plant wastes landfill on the environment, methods of protection. Energetics, 10, 557-562 (in Polish).

Choi S.K., Lee S., Song Y.K., Moon H.S., 2002. Leaching characteristics of selected Korean fly ashes and its implications for the groundwater composition near the ash disposal mound. Fuel, 81, 1083-1090. DOI: 10.1016/S0016-2361(02)00006-6.

Hycnar J.J., Szczygielski T., 2008. Perspectives for the coal combustion-based power industry. The International Conference Eurocoalash. Warsaw, Poland, 6-8 October 2008, 87- 101 (in Polish).

Hycnar J.H., Szczygielski T., Jarema-Suchorowska S., 2010. Ash landfills from coal combustion source of minerals. The Conference on Energy Industry Ash. Warsaw, Poland, 24-26 October 2010, 311-325 (in Polish).

Kapuściński T., Strzałkowska E., 2005. Extraction of basic and trace elements from combustion wastes located in mining excavations. Miner. Resour. Manage., 21, Book 3, 37- 46 (in Polish).

Klojzy-Kaczmarczyk B., Mazurek J. 2003. Effect of leachate from municipal and industrial landfills on the quality of the aquatic environment. Technical Transactions, 94-97: 5-12 (in Polish).

Kwiatkowska B., Cierpiszewski R., Domka F., 2006. The effect of acid precipitations on the texture of fly ashes and the content of bioavailable metals. Ecol. Technol., 14, 53-58 (in Polish).

Lecuyer I., Bicocchi S., Ausset P., Lefever R., 1996. Physico-chemical characterization and leaching of desulphurization coal fly ash. Waste Manage. Res., 14, 15-28. DOI: 10.1177/0734242X9601400103. 
Łączny M.J., Adamski M., 2002. Ion transport model of the energetic wastes. The Works and Studies of IPIŚ PAN 2001 no. 56, Ossolineum Publishers, Zabrze 2002 (in Polish).

Quant B., 2000. Sludge from municipal waste water treatment plants in retreating the grate waste storage yards. Ecol. Technol., 8, 95-99 (in Polish).

Rosik-Dulewska Cz., Karwaczyńska U., 2008. Methods of leaching contaminants from mineral waste in the aspect of its potential utilization in hydrotechnical construction. Middle Pomeranian Scientific Society of the Environment Protection, Annual Set The Environment Protection, 10, 205-219 (in Polish).

Sambor A., Szymanek A., 2012. Investigation of the distribution of chemical components in selected landfill layers. and fly ash fractions. Chem. Process Eng., 33, 221-229. DOI: 10.2478/v10176-012-0019-9.

Strzałkowska E., 2004. Impact of coal combustion technology to flue gas desulphurization used in power plant "Laziska" on the properties of formed slags and ashes in terms of their impact on the environment. PhD thesis, University of Silesia, Gliwice 2004.

Uliasz-Bocheńczyk U., Majchrzak H., Mokrzycki E., 2010. The prospects of hard and brown coal in Poland and in the European Union. 21 The World Energy Congress in Montreal. Canada, Mining Overview, 12-16 September, 2010, 3-4.

Watanabe Y., Tanosaki T., Ishikawa Y., Lin J., 2008. Characterization of fly ash in terms of impact on the environment - the case of the East Asian region. The International Conference EUROCOALASH. 6-8 October 2008, Warsaw, 42-69.

Woźniak M., Żygadło M., 2002. Assessing the influence of climate factors on the chemical stability of fly ash deposited on wet landfills. Ochrona Środowiska, 2, 17- 21 (in Polish).

Woźniak M., Klisik A., 2007. Impact on groundwater leachate from ash landfills. The Cracow Conference of Young Scientists 2007. 369-376 (in Polish).

Received 21 February 2013

Received in revised form 13 March 2014

Accepted 21 May 2014 